\title{
Substrate-Selectivity in Catalytic Photooxygenation Processes using a Quinine-BODIPY System
}

\author{
Jérôme Fischer ${ }^{\mathrm{a}}$ \\ Hélène Serier-Brault ${ }^{\mathrm{b}}$ \\ Pierrick Nun ${ }^{\mathrm{a}}$ \\ Vincent Coeffard*a \\ a Université de Nantes, CEISAM UMR CNRS 6230, F-44000, \\ Nantes - France. \\ ${ }^{\mathrm{b}}$ Institut des Matériaux Jean Rouxel, Université de Nantes, \\ CNRS, 2 rue de la Houssinière, BP 32229, 44322 Nantes - \\ France.
}

vincent.coeffard@univ-nantes.fr

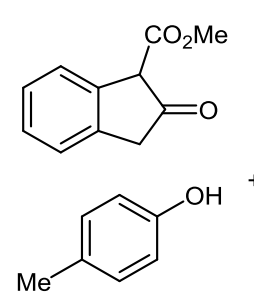

up to 4 substrates

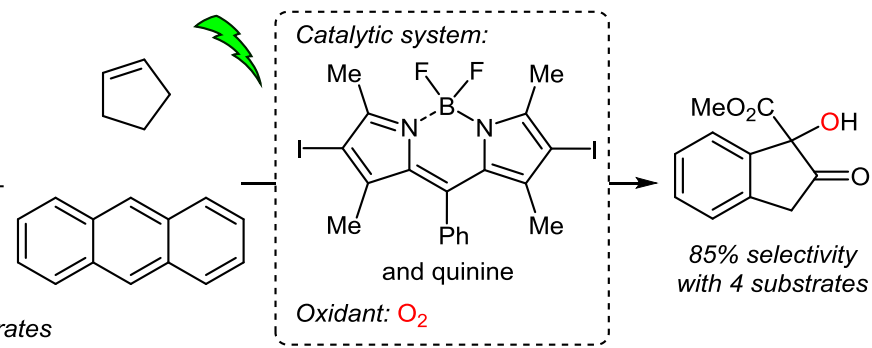

Abstract Substrate selectivity by means of synthetic catalysts remains a challenging topic in chemistry. Here, a catalytic system combining a iodoBODIPY photosensitizer and quinine was evaluated in the competitive photooxygenation of non- and hydrogen-bond donor substrates. The ability of quinine to activate hydrogen-bond donor substrates towards photooxygenation was reported and the results were benchmarked with photooxygenation experiments in the absence of quinine.

Key words photooxygenation, singlet oxygen, substrate-selectivity, BODIPY oxidation

The synthetic chemist community has been resourceful and inventive in making catalytic systems more selective and efficient to allow for the construction of densely functionalized architectures. ${ }^{1}$ In spite of extensive efforts, substrate-selectivity with artificial catalysts continues to attract considerable attention. ${ }^{2,3}$ The challenge is even more difficult when highly reactive reagents such as singlet oxygen are involved in the functionalization of molecular scaffolds. Singlet oxygen $\left({ }^{1} \mathrm{O}_{2}\right)$ is a powerful oxidant which is conveniently produced by sensitization of ground state triplet oxygen under illumination of a photosensitizer. ${ }^{4}$ Photooxygenation is a leading method for introducing oxygen atoms in organic compounds but the control of chemo-, regio-, stereo- or substrate-selectivity remains a challenging task. ${ }^{5-7}$

One approach in which these demands can be achieved is through the use of two-module photosensitizers with a controlled delivery of singlet oxygen. The guiding philosophy is that one module of the photosensitizer is dedicated to the production of singlet oxygen and the second unit modulates singlet oxygen generation efficiency depending on the surrounding environment. ${ }^{8}$ Parameters such as acidity and ion concentrations have been harnessed for controlling the production of singlet oxygen and these strategies hold great promises for photodynamic therapy. ${ }^{9}$

From a synthetic standpoint, our group has recently described a two-unit photosensitizer aiming at performing asymmetric hydroxylation of $\beta$-dicarbonyl compounds. ${ }^{10}$ The photosensitizer contains a iodo-BODIPY part enabling the production of singlet oxygen under green light illumination and a quinine unit playing a double role. The substrates are activated towards photooxygenation by quinine while in the absence of substrates in the active site of quinine, singlet oxygen is physically quenched by the quinuclidine nitrogen atom. ${ }^{11}$ In light of these results, we surmised that photooxygenation in the presence or absence of quinine could be applied to substrateselective catalysis in which the substrates involved contain different reacting functionalities. To put this strategy into practice, we envisaged two plausible scenarios (Figure 1). In a mixture of compounds with $(\mathrm{AH})$ and without hydrogen-bond donor functional groups (B), photooxygenation in the presence of a catalytic system iodo-BODIPY/quinine would selectively oxidised $\mathrm{AH}$ owing to the hydrogen-bond activation by the quinuclidine nitrogen atom. ${ }^{12}$ On the contrary, substrate $B$ would not be oxidised due to physical deactivation of singlet oxygen by quinine. The only use of iodo-BODIPY would offer a complementary route by preferentially oxidising the substrate $B$ deprived of hydrogen-bond donor opportunities.

The initial study was focused on discovering the best quinine derivatives able to physically quench singlet oxygen. To this aim, we first investigated the photooxygenation of the non-hydrogen bond donor anthracene which is a ${ }^{1} \mathrm{O}_{2}$ chemical trap (Figure 2). Irradiation for $45 \mathrm{~min}$ in the presence of $5 \mathrm{~mol} \%$ of $\mathbf{1}$ led to $90 \%$ ${ }^{1} \mathrm{H}$ NMR yield of anthracene-9,10-endoperoxide 5. Performing the same reaction in the presence of $5 \mathrm{~mol} \%$ quinine led to a dramatic decrease in singlet oxygen insertion. Analysis of the reaction mixture showed the formation of anthracene-9,10endoperoxide in only $33 \%$ NMR yield at the end of reaction. 
Our previous Work: Asymmetric Photooxygenation ${ }^{[10]}$

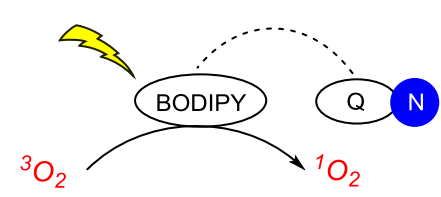

Role of Quinine (Q): i) Physical deactivation of

${ }^{1} \mathrm{O}_{2}$ (OFF mode)

ii) asymmetric induction

and substrate activation

towards ${ }^{1} \mathrm{O}_{2}$ (ON mode)

This Work: Substrate-Selective Photooxygenation of hydrogen bond donor $(\mathrm{AH})$ and non-hydrogen bond donor substrates $(\mathrm{B})$
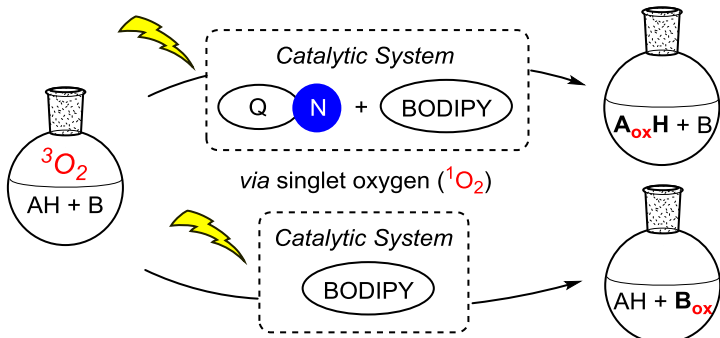

Figure 1 Concept: Substrate-selective photooxygenation using a catalytic combination of iodo-BODIPY and quinine.

As reported in literature, ${ }^{10}$ the quinuclidine heterocyclic framework plays a crucial role in singlet oxygen deactivation because similar results were obtained by running the photooxygenation with $5 \mathrm{~mol} \%$ of commercially available quinuclidine. Surprisingly, the use of bifunctional photosensitizer 2 which has been recently prepared by our group provided the product in $74 \%$ yield after 45 min reaction time. ${ }^{10}$ Linking the BODIPY $\mathbf{1}$ to the quinine heterocycle led to a higher photooxygenation activity than performing the reaction using an equimolar amount of quinine and $\mathbf{1}$. In light of these results, we surmised that substitution of the terminal alkene of quinine could influence the photooxygenation rate of anthracene. A mixture of $\mathbf{1}$ (5 mol\%) and $\mathbf{3}$ (5 $\mathrm{mol} \%$ ) is catalytically active and the reaction is faster than performing the photooxygenation with the catalytic system 1 (5 mol\%) and quinine ( 5 mol\%). ${ }^{13}$ The replacement of the phenyl ring in 3 by a bulkier group (4) affects the catalytic activity by increasing the photooxygenation rate. ${ }^{14}$ These results demonstrated the unexpected influence of the alkene functionalization on the photooxygenation activity.

Based on this study, quinine was chosen as the best additive to investigate substrate-selective catalysis owing to its strong ability to physically deactivate singlet oxygen when non hydrogen-bond donor substrate are involved. We then explored the ability of the BODIPY 1/quinine system to selectively oxidise hydrogen-bond donor substrates within the context of substrate-selective catalysis. In order to tackle this challenge, competitive photooxygenations of $1 / 1$ mixtures of methyl-2-oxo-1-indanecarboxylate and non-hydrogen bond donor substrates were performed (Scheme 1). ${ }^{15}$ The ability of the BODIPY 1/quinine catalytic system to selectively oxidise hydrogen-bond donor substrates was first investigated by pairwise competitive experiments between methyl-2-oxo-1indanecarboxylate, which is prone to oxidation by the BODIPY 1/quinine combination, ${ }^{10}$ and anthracene. Selective photooxygenation was observed and the alcohol 6a was obtained in $79 \%$ yield while $\mathbf{5}$ was not detected. The low quinine loading (5 mol\%) required for preventing the photooxygenation

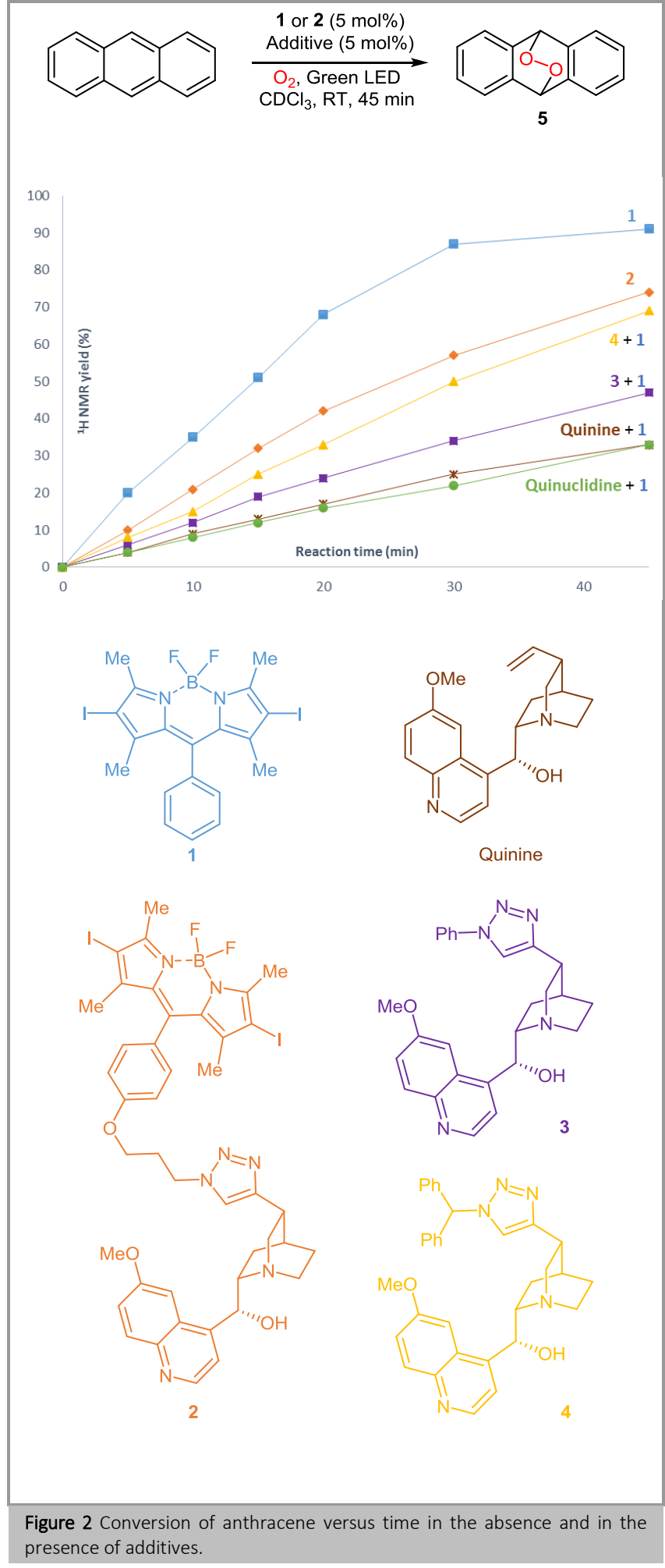

of anthracene is well explained by comparing the values of rate constants for the chemical reaction and physical deactivation of singlet oxygen $\left(\mathrm{k}_{\mathrm{T}}\right)$. Singlet oxygen is quenched by anthracene with $\mathrm{k}_{\mathrm{T}}=5.4 \times 10^{5} \mathrm{M}^{-1} \mathrm{~s}^{-1}\left(\mathrm{CHCl}_{3}\right)$ while $\mathrm{k}_{\mathrm{T}}$ value for quinine is a 42.5 factor larger $\left(\mathrm{kT}_{\mathrm{T}}=2.3 \times 10^{7} \mathrm{M}^{-1} \mathrm{~s}^{-1}\right.$ in $\left.\mathrm{CHCl}_{3}\right) .{ }^{16}$ To investigate the potential formation of a complex between methyl-2-oxo-1-indanecarboxylate and quinine, NMR titration experiments were carried out (see supporting information for details). From these data, a Job plot analysis (Figure 3) was performed which supports the formation of a 1:1 complex with an association constant Ka $=18.9 \quad \mathrm{M}^{-1}$. 
a) $\beta$-Ketoester and anthracene<smiles>CC(=O)C1C(=O)Cc2ccccc21</smiles><smiles>c1ccc2cc3ccccc3cc2c1</smiles>

Methyl-2-oxo1-indanecarboxylate

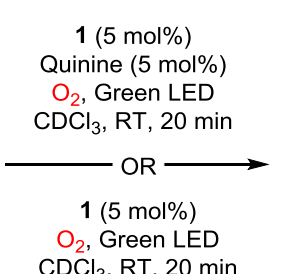

$\mathrm{CDCl}_{3}, \mathrm{RT}, 20 \mathrm{~min}$

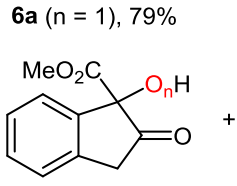

$6 \mathbf{b}(n=2), 13 \%$
5, $0 \%$<smiles>c1ccc2c(c1)C1OOC2c2ccccc21</smiles>

$5,36 \%$

b) $\beta$-Ketoester and cyclopentene

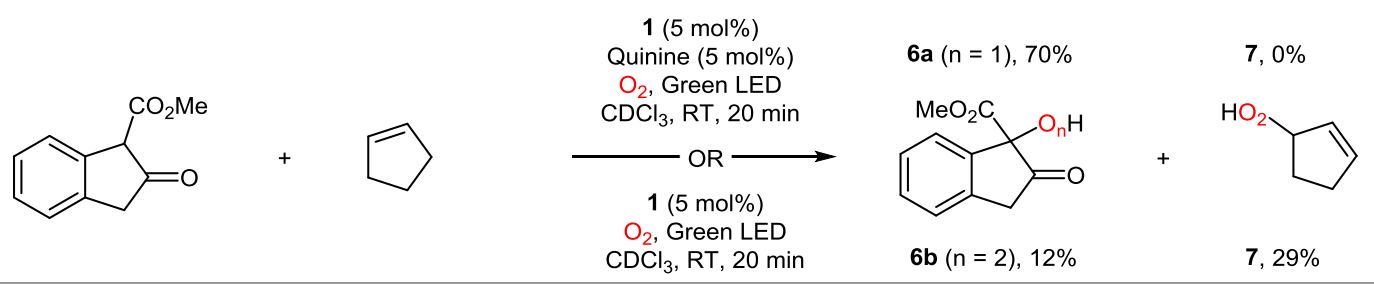

Scheme 1 Competitive photooxygenation of reaction mixtures containing equimolar amounts of methyl-2-oxo-1-indanecarboxylate and non-hydrogen bond donor substrates. Substrate-selectivity was determined as product ratio for a better reliability. NMR yields for each product are reported by using an internal standard.

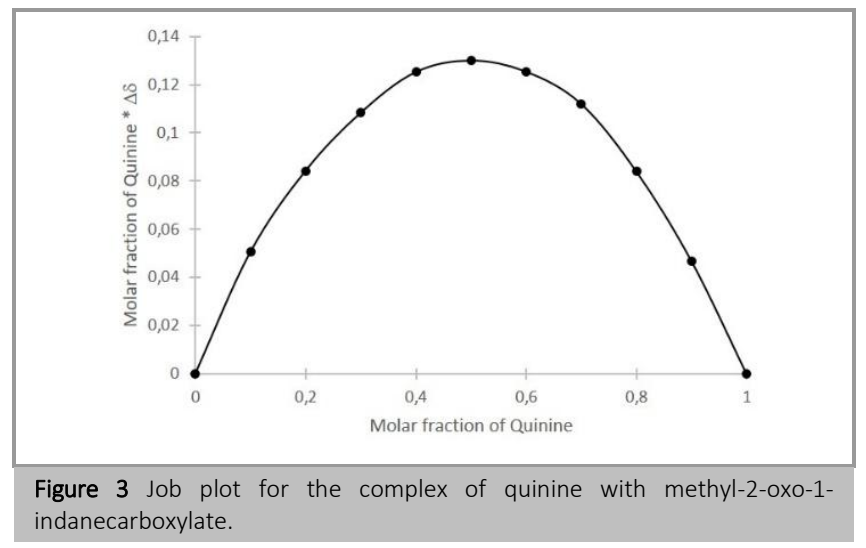

From these results and literature data, ${ }^{10}$ a plausible mechanism is shown in Scheme 2 to explain the formation of alcohol $\mathbf{6 a}$. The first step would involve the formation of the adduct $\mathbf{B}$ of quinine and methyl-2-oxo-1-indanecarboxylate for which the enol form

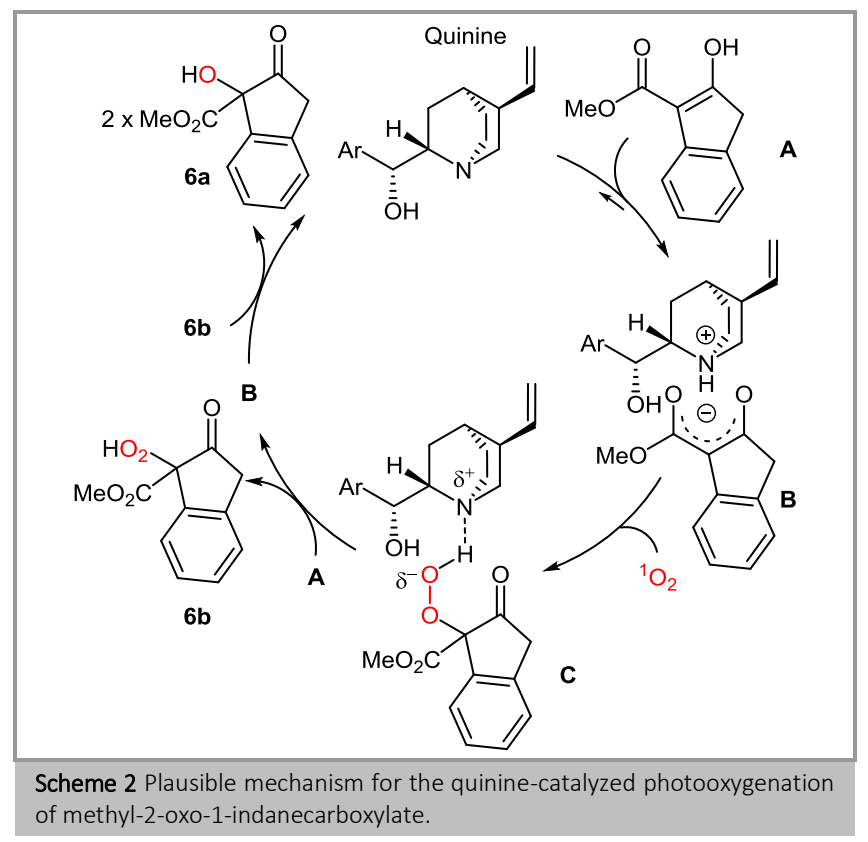

(A) is the major form in $\mathrm{CDCl}_{3}$. The formation of complex $\mathbf{B}$ would enhance the reactivity of the enolic system towards singlet oxygen and the intermediate $\mathbf{C}$ would be produced leading to the hydroperoxide $\mathbf{6 b} \cdot{ }^{17}$ As previously reported for a similar transformation, ${ }^{18}$ the hydroperoxide $\mathbf{6 b}$ could react with the complex B to form alcohol 6a. In light of NMR studies, a complex could also exist between 6a and quinine (see supporting information). The results obtained with a BODIPY 1/quinine combination were compared with the photooxygenation promoted by BODIPY 1 (Scheme 1, a). In the absence of quinine, a mixture of hydroperoxide $\mathbf{6 b}$ and anthracene-9,10-endoperoxide $\mathbf{5}$ was observed without any traces of alcohol 6a. Using the same reaction conditions, a pair-wise competitive experiment was also performed on an equimolar mixture of methyl-2-oxo-1-indanecarboxylate and cyclopentene prone to react with singlet oxygen through enereaction (Scheme 1, b). ${ }^{19}$ In the presence of quinine, compound 6a was selectively formed in $70 \%$ yield. Irradiation in the presence of BODIPY $\mathbf{1}$ showed that a mixture of hydroperoxides $\mathbf{6 b}$ and $\mathbf{7}$ were obtained in $12 \%$ and $29 \%$ yields, respectively. In order to investigate another family of hydrogen-bond donor substrates, competitive experiments between para-cresol and cyclopentene were studied (Scheme 3). A rapid screening of quinine amount showed that the best selectivities were obtained with $40 \mathrm{~mol} \%$ of quinine. Under these conditions, a higher substrate selectivity of $\mathbf{8 a}$ and $\mathbf{8 b}$ over $\mathbf{7}$ was observed. NMR titration showed the formation of a 1:1 complex with para-cresol and quinine with $\mathrm{Ka}=28.2 \mathrm{M}^{-1}$ (see supporting information for details). By increasing the electron density of the phenyl ring, the formation of this adduct could explain the higher reactivity of para-cresol towards singlet oxygen. ${ }^{16 \mathrm{~b}}$ The ability of quinine to reduce peroxy quinol $\mathbf{8 b}$ explains the formation of $\mathbf{8 a} .^{20} \mathrm{~A}$ reversal of selectivity was noticed in the absence of quinine highlighting its importance in the reaction outcome. A similar scenario was observed by investigating the photooxygenation of a mixture of para-cresol and anthracene. Antracene-9,10-endoperoxide $\mathbf{5}$ was preferentially formed by using BODIPY $\mathbf{1}$ as a photosensitizer while photooxygenation of para-cresol is faster than anthracene when $5 \mathrm{~mol} \%$ of quinine was added. In light of 


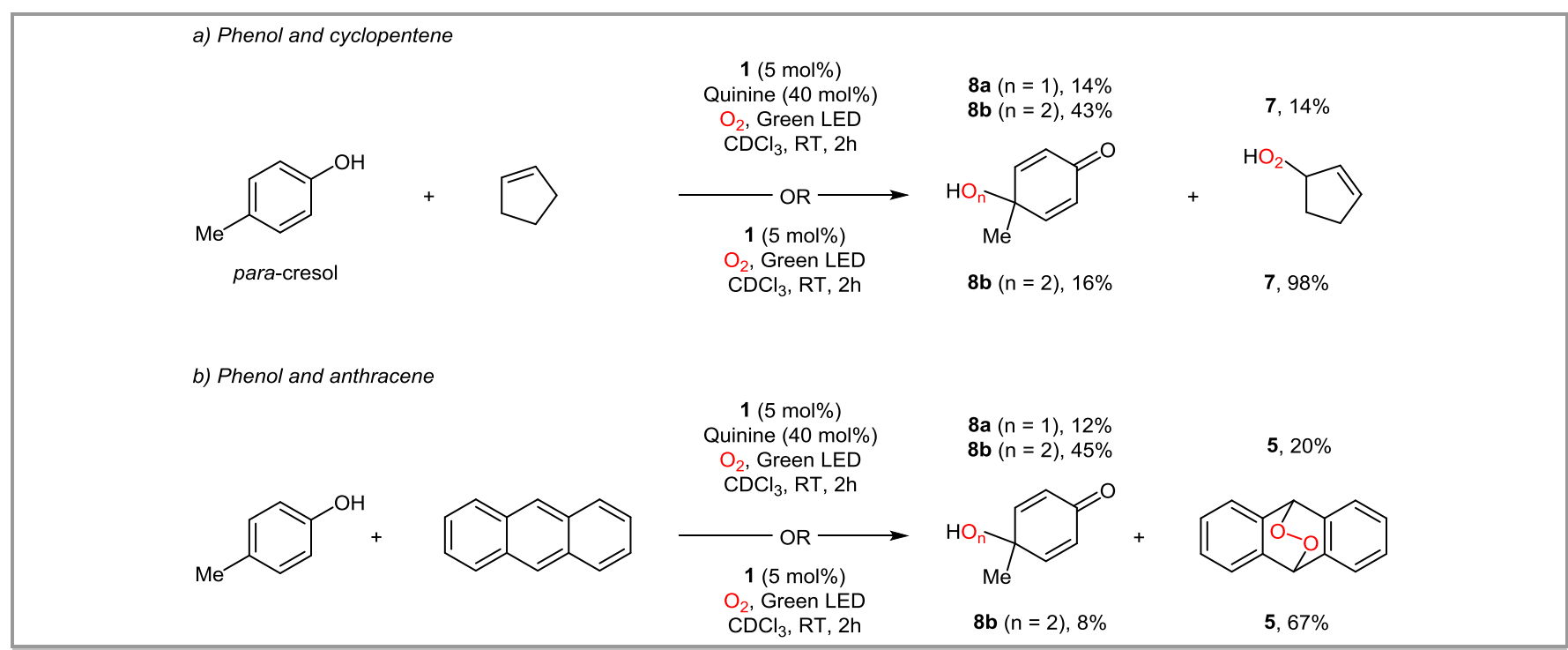

Scheme 3 Competitive photooxygenation of reaction mixtures containing equimolar amounts of para-cresol and non-hydrogen bond donor substrates. Substrateselectivity was determined as product ratio for a better reliability. NMR yields of each product are reported by using an internal standard.

Photooxygenation using a mixture of BODIPY and quinine (20 mol\%) afforded selectively the alcohol $\mathbf{6 a}$ in $96 \%$ yield while only traces amount of the other products were detected. Therefore, a substrate selectivity of $85 \%$ measured as product ratio was calculated. These reaction conditions were benchmarked against photooxygenation without quinine as an additive. As expected, oxidation of hydrogen-bond donor substrates, namely para-cresol and methyl-2-oxo-1indanecarboxylate, were slower than photooxygenation of cyclopentene and anthracene. As a result, a complex reaction mixture of $\mathbf{6 b}(15 \%), 7(30 \%)$ and 5 (48\%) was obtained highlighting the crucial role of quinine in substrate-selectivity.
To conclude, the results obtained in this study have clearly shown the importance of quinine as a catalytic additive in the photooxygenation outcome. Within the context of substrateselective catalysis, pair-wise competitive photooxygenation experiments were performed using a BODIPY photosensitizer with or without quinine. We demonstrated that a selection of hydrogen-bond donor substrates was selectively oxidised in the presence of quinine. On the contrary, singlet-oxygen mediated oxidations of non-hydrogen bond donor substrates such as anthracene or cyclopentene were faster without addition of quinine which confirmed the singlet oxygen quenching role of quinine. 
<smiles>CC(=O)C1C(=O)Cc2ccccc21</smiles><smiles>C1=CCCC1</smiles>

\section{1 (5 mol\%)} Quinine (20 $\mathrm{mol} \%$ ) $\mathrm{O}_{2}$, Green LED $\mathrm{CDCl}_{3}, \mathrm{RT}, 20 \mathrm{~min}$<smiles>Cc1ccc(O)cc1</smiles>
$\mathrm{Me}$

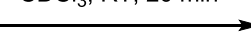<smiles>CC(=O)C1C(=O)Cc2ccccc21</smiles><smiles>C1=CCCC1</smiles>

$1(5 \mathrm{~mol} \%)$ $\mathrm{O}_{2}$, Green LED $\mathrm{CDCl}_{3}, \mathrm{RT}, 20 \mathrm{~min}$<smiles>Cc1ccc(O)cc1</smiles><smiles>c1ccc2cc3ccccc3cc2c1</smiles><smiles>OC1C=CCC1</smiles>

7, $0 \%$
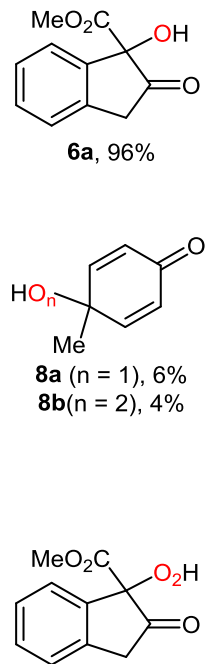

6a, $96 \%$

6b, $15 \%$<smiles>O=C1C=CC(O)([N+]([O-])[Na])C=C1</smiles><smiles>c1ccc2c(c1)C1OC2c2ccccc21</smiles>

5, $9 \%$
$\mathrm{HO}_{2}$<smiles>CC1C=CCC1</smiles>

7, $30 \%$<smiles>c1ccc2c(c1)C1OC2c2ccccc21</smiles>

$5,48 \%$

Scheme 4 Competitive photooxygenation of an equimolar pool of substrates. NMR yields are reported by using an internal standard.

Therefore, the catalytic system for a photooxidative transformation must be carefully selected by considering the nature of the substrates. Work is in progress to shed the light on the importance of the alkene functionalization of quinine on photooxygenation efficiency.

\section{Funding Information}

This work was supported by The Région Pays de la Loire (NANO2 project) which financed a PhD grant for JF. We also thank University of Nantes and CNRS for financial support.

\section{Supporting Information}

YES (this text will be updated with links prior to publication)

\section{Primary Data}

NO (this text will be deleted prior to publication)

\section{References and Notes}

(1) Ward, R. S. Selectivity in Organic Synthesis; John Wiley and Sons: West Sussex, England, 1999.

(2) Lindbäck, E.; Dawaigher, S.; Wärnmark, K. Chem. Eur. J. 2014, 20 13432.

(3) For selected examples, see: (a) Olivo, G.; Capocasa, G.; Lanzalunga, O.; Di Stefano, S.; Costas, M. Chem. Commun. 2019, 55, 917. (b) Zardi, P.; Roisnel, T.; Gramage-Doria, R. Chem. Eur. J. 2019, 25, 627. (c) Chavagnan, T.; Bauder, C.; Sémeril, D.; Matt, D.; Toupet, L. Eur. J. Org. Chem. 2017, 70. (d) Wang, Q.-Q.; Gonell, S.; Leenders, S. H. A. M.; Dürr, M.; Ivanović-Burmazović, I.; Reek, J. N. H. Nature Chem. 2016, 8, 225. (e) Lindbäck, E.; Cherraben, S.; Francoïa, J.-P.; Sheibani, E.; Lukowski, B.; Proñ, A.; Norouzi-Arasi, H.; Månsson, K.; Bujalowski, P.; Cederbalk, A.; Pham, T. H.; Wixe, T.; Dawaigher, S.; Wärnmark, K. ChemCatChem 2015, 7, 333.

(4) (a) Pibiri, I.; Buscemi, S.; Palumbo Piccionello, A.; Pace, A ChemPhotoChem 2018, 2, 535. (b) Nonell, S.; Flors, C. Eds., Singlet
Oxygen: Applications in Biosciences and Nanosciences, The Royal Society Of Chemistry, 2016.

(5) Montagnon, T.; Kalaitzakis, D.; Sofiadis, M.; Vassilikogiannakis, G. Org. Biomol. Chem. 2016, 14, 8636.

(6) For recent examples of asymmetric photooxygenation, see: (a) Tang, X.-F.; Zhao, J.-N.; Wu, Y.-F.; Feng, S.-H.; Yang, F.; Yu, Z.-Y.; Meng, Q.-W. Adv. Synth. Catal. 2019, 361, 5245. (b) Yang, F.; Zhao, J.; Tang, X.; Wu, Y.; Yu, Z.; Meng, Q. Adv. Synth. Catal. 2019, 361, 1673. (c) Walaszek, D. J.; Jawiczuk, M.; Durka, J.; Drapała, O.; Gryko, D. Beilstein J. Org. Chem. 2019, 15, 2076. (d) Tang, X.; Feng, S.; Wang, Y.; Yang, F.; Zheng, Z.; Zhao, J.; Wu, Y.; Yin, H.; Liu, G.; Meng, Q. Tetrahedron 2018, 74, 3624. (e) Ding, W.; Lu, L.-Q.; Zhou, Q.-Q.; Wei, Y.; Chen, J.-R.; Xiao, W.-J. J. Am. Chem. Soc. 2017, 139, 63. (f) Wang, Y.; Yin, H.; Tang, X.; Wu, Y.; Meng, Q.; Gao, Z. J. Org. Chem. 2016, 81, 7042. (g) Wang, Y.; Zheng, Z.; Lian, M.; Yin, H.; Zhao, J.; Meng, Q.; Gao, Z. Green Chem. 2016, 18, 5493. (i) Walaszek, D. J.; Rybicka-Jasińska, K.; Smoleń, S.; Karczewski, M.; Gryko, D. Adv. Synth. Catal. 2015, 357, 2061.

(7) Bayer, P.; Pérez-Ruiz, R.; Jacobi von Wangelin, A. ChemPhotoChem 2018, 2, 559 .

(8) Cló, E.; Snyder, J. W.; Ogilby, P. R.; Gothelf, K. V. ChemBioChem 2007, 8, 475 .

(9) Callaghan, S.; Senge, M. O. Photochem. Photobiol. Sci. 2018, 17, 1490.

(10) Fischer, J.; Mele, L.; Serier-Brault, H.; Nun, P.; Coeffard, V. Eur. J. Org. Chem. 2019, 6352.

(11) Lemp, E.; Günther, G.; Castro, R.; Curitol, M.; Zanocco, A. L. J. Photochem. Photobiol. A 2005, 175, 146.

(12) For the use of BODIPY derivatives in photooxygenation, see: (a) Mauger, A.; Farjon, J.; Nun, P.; Coeffard, V. Chem. Eur. J. 2018, 24, 4790. (b) Huang, L.; Zhao, J.; Guo, S.; Zhang, C.; Ma, J. J. Org. Chem. 2013, 78, 5627.

(13) Experimental procedure and analytical data for compound 3: Azidobenzene (417 mg, $3.5 \mathrm{mmol}, 1$ equiv) and 10,11didehydroquinine (375 mg, $1.16 \mathrm{mmol}, 0.33$ equiv) were dissolved in a THF $/ \mathrm{H}_{2} \mathrm{O} 3 / 1$ mixture $(10.2 / 3.4 \mathrm{~mL})$ in a Schlenk flask. Sodium ascorbate ( $95.1 \mathrm{mg}, 0.48 \mathrm{mmol}, 0.133$ equiv), then copper sulfate pentahydrate $(30 \mathrm{mg}, 0.12 \mathrm{mmol}, 0.033$ equiv) were added and the reaction mixture was stirred at room 
temperature for $72 \mathrm{~h}$. The solution was concentrated in vacuo, and the resultant slurry was dissolved in dichloromethane $(60$ $\mathrm{mL})$. The organic phase was washed with water $(3 \times 60 \mathrm{~mL})$, dried over magnesium sulfate and concentrated in vacuo. Purification by column chromatography, eluting with 8:2 ethyl acetate:methanol, gave the quinine derivative 3 (178 $\mathrm{mg}, 35 \%)$. M.p 217-220 ${ }^{\circ} \mathrm{C} ; \delta_{\mathrm{H}}\left(300 \mathrm{MHz}, \mathrm{CDCl}_{3}\right) 8.61(1 \mathrm{H}, \mathrm{d}, J 4.5), 7.94(1 \mathrm{H}$, d, J 9.9), 7.62-7.55 (3H, m), 7.52-7.48 (1H, m), 7.48-7.41 $(2 \mathrm{H}, \mathrm{m})$, 7.40-7.34 (1H, m), 7.33-7.27 (2H, m), $5.56(1 \mathrm{H}, \mathrm{d}, J 4.7), 3.89(3 \mathrm{H}$, s), 3.57-3.44 $(1 \mathrm{H}, \mathrm{m}), 3.44-3.35(1 \mathrm{H}, \mathrm{m}), 3.35-3.27(2 \mathrm{H}, \mathrm{m}), 3.13$ $3.05(1 \mathrm{H}, \mathrm{m}), 2.79-2.67(1 \mathrm{H}, \mathrm{m}), 2.21-2.14(1 \mathrm{H}, \mathrm{m}), 1.91-1.72(2 \mathrm{H}$, $\mathrm{m}), 1.71-1.58(1 \mathrm{H}, \mathrm{m}), 1.58-1.45(1 \mathrm{H}, \mathrm{m}), 0.96-0.79(1 \mathrm{H}, \mathrm{m}) ; \delta_{c}$ (75 MHz, $\left.\mathrm{CDCl}_{3}\right)$ 157.9, 151.6, 147.7, 147.6, 144.4, 137.2, 131.6, 129.8 (2C), 128.7, 126.9, 121.6, 120.5 (2C), 118.7, 118.6, 101.7, $77.4,71.9,59.9,56.5,55.9,43.3,33.3,28.0,27.6,22.3$; IR (ATR) $/ \mathrm{cm}^{-1} 3160,3149,2935,1505,1227,1015,767,762$; HRMS (ESI) Calcd for $\mathrm{C}_{26} \mathrm{H}_{28} \mathrm{~N}_{5} \mathrm{O}_{2}[\mathrm{M}+\mathrm{H}]^{+}: 442.2243$ found: 442.2235 .

(14) Experimental procedure and analytical data for compound 4 Reaction conditions described for the synthesis of $\mathbf{3}$ was applied to the preparation of $\mathbf{4}$ but diphenylmethyl azide $(731 \mathrm{mg}, 3.5$ mmol, 1 equiv) was used instead of azidobenzene. Purification by column chromatography, eluting with 85:15 ethyl acetate:methanol, gave the quinine derivative 4 (255 $\mathrm{mg}, 41 \%)$. M.p $114^{\circ} \mathrm{C}$; $\delta_{\mathrm{H}}\left(300 \mathrm{MHz} \mathrm{CDCl}_{3}\right) 8.64(1 \mathrm{H}, \mathrm{dd}, J 4.51 .9), 7.92(1 \mathrm{H}$, d, J 9.4), $7.51(1 \mathrm{H}, \mathrm{d}, J$ 4.8), 7.34-7.22 (7H, m), 7.22-7.17 (1H, m), $7.01(1 \mathrm{H}, \mathrm{s}), 6.96-6.88(5 \mathrm{H}, \mathrm{m}), 5.66(1 \mathrm{H}, \mathrm{d}, J 3.9), 3.81(3 \mathrm{H}, \mathrm{s})$, 3.70-3.56 (1H, m), 3.46-3.32 (2H, m), 3.31-3.20 (1H, m), 3.08-2.98 $(1 \mathrm{H}, \mathrm{m}), 2.81-2.66(1 \mathrm{H}, \mathrm{m}), 2.12-2.04(1 \mathrm{H}, \mathrm{m}), 1.87-1.70(2 \mathrm{H}, \mathrm{m})$, 1.68-1.53 (1H, m), 1.40-1.31 (1H, m), 0.96-0.81 (1H, m); $\delta \mathrm{c}(75$ $\left.\mathrm{MHz}_{\mathrm{CDCl}}\right)$ 157.9, 150.1, 147.6, 146.9, 144.4, 138.2, 138.1, 131.7, 129.0 (2C), 128.9 (2C), 128.6, 128.5, 128.1 (2C), 127.9 (2C), 126.7, $121.8,120.6,118.6,101.2,71.2,68.1,59.6,55.8,43.4,33.2,29.8$, 28.1, 27.1, 21.8; IR (ATR)/ $\mathrm{cm}^{-1} 3143,2926,2874,1506,1238$,
1028, 725, 698; HRMS (ESI) Calcd for $\mathrm{C}_{33} \mathrm{H}_{34} \mathrm{~N}_{5} \mathrm{O}_{2}[\mathrm{M}+\mathrm{H}]^{+}$: 532.2713 found: 532.2716 .

(15) Representative experimental procedure for the pair-wise competitive photooxygenation experiments: To a Schlenk flask was added anthracene ( $0.21 \mathrm{mmol}, 37.4 \mathrm{mg}, 1$ equiv), methyl 2-oxoindane 1 -carboxylate $(0.21 \mathrm{mmol}, 40 \mathrm{mg}, 1$ equiv $)$ photosensitizer 1 ( $0.0105 \mathrm{mmol}, 6 \mathrm{mg}, 5 \mathrm{~mol} \%)$, methyl phenyl sulfone ( $0.105 \mathrm{mmol}, 16.4 \mathrm{mg}, 0.5$ equiv) as an internal standard and $\mathrm{CDCl}_{3}(4.2 \mathrm{~mL})$ to give a red solution. The reaction medium was gently bubbled for $5 \mathrm{~min}$ and then placed under oxygen atmosphere. The homogeneous solution was irradiated with two green LEDs ( $1 \mathrm{~W}, 75 \mathrm{Lm}, 535 \mathrm{~nm}$ typical wavelength). The distance from the light source to the irradiation Schlenk vessel was $2 \mathrm{~cm}$ without the use of any filters. The reaction was stirred for the appropriate reaction time and an aliquot $(0.2 \mathrm{~mL})$ was taken from the reaction mixture. The aliquot was diluted with $\mathrm{CDCl}_{3}(0.4 \mathrm{~mL})$ and nitrogen was bubbled through the solution to remove oxygen. The samples were then analyzed by ${ }^{1} \mathrm{H}$ NMR to determine the yield and product formation.

(16) (a) Lemp, E.; Valencia, C.; Zanocco, A. L. J. Photochem. Photobiol. A 2004, 168, 91. (b) Wilkinson, F.; Helman, W. P.; Ross, A. B. J. Phys. Chem. Ref. Data 1995, 24, 663.

(17) For a reference dealing with the reactivity of singlet oxygen with enols, see: Wasserman, H. H.; Pickett, J. E. Tetrahedron 1985, 41, 2155.

(18) Lian, M.; Li, Z.; Cai, Y. ; Meng, Q. ; Gao, Z. Chem. Asian J. 2012, 7, 2019.

(19) For selected reviews about Schenck-ene reactions, see: (a) Alberti, M. N.; Orfanopoulos, M. Synlett 2010, 999. (b) Clennan, E. L. Tetrahedron 2000, 56, 9151.

(20) See supporting information. For the reduction of hydroperoxides with tertiary amine, see: Jones, K. M.; Hillringhaus, T.; Klussmann, M. Tetrahedron Lett. 2013, 54, 3294. 